\title{
Occurrence of health-compromising protozoan and helminth infections in tortoises kept as pet animals in Germany
}

Malek J. Hallinger ${ }^{1,2^{*}}$, Anja Taubert ${ }^{1}$, Carlos Hermosilla ${ }^{1}$ and Frank Mutschmann ${ }^{2}$

\begin{abstract}
Background: Exotic reptiles such as tortoises, have become increasingly common domestic pets worldwide and are known to host different gastrointestinal parasites. Some of these parasites bear zoonotic potential. In the present survey, we parasitologically examined tortoise faecal samples $(n=1005)$ from 19 different species held as pets in private German households and German zoological gardens.

Methods: Saline faecal smears were used to generate prevalence data for potentially health-compromising gastrointestinal parasites. In addition, we performed complete parasitological dissections of dead tortoises $(n=49)$ to estimate endoparasite burdens precisely.

Results: Analysed tortoise faecal samples contained a broad spectrum of endoparasites. We detected ten taxa of endoparasites; oxyurid nematodes (e.g. Tachygonetria spp.) were the most prevalent parasites in faecal samples (43.18\%), followed by ascarids (Angusticaecum spp.) (0.01\%), Hexamita spp. (0.007\%), Balantidium spp. (0.007\%), trichomonads (0.004\%), Strongyloides spp. (0.003\%), Entamoeba spp. (0.005\%), Hartmanella spp. (0.001\%), Blastocystis spp. (0.002\%), heterakids (0.001\%) and Trimitus spp. (0.001\%). Additionally, we investigated dead tortoise individuals ( $n=49$; of 10 different species) for aetiological diagnosis and estimation of endoparasite burden. Of these individuals, 38 (77.6\%) were infected with parasites and 14 (28.6\%) of them died most probably due to severe parasitic infection. Oxyurid infections correlated positively with calcium deficiency and metabolic bone disease (MBD) as well as nephrosis/nephritis, mainly occurring in juvenile tortoises ( $<5$ years of age).

Conclusions: The saline faecal smear technique proved to be efficient in detecting different metazoan and protozoan parasite stages in tortoise faeces. The prevalence of oxyurid infections was particularly high. In combination with pathological findings in clinical oxyuridosis obtained from necropsied animals, our findings call for further, detailed investigations on pathogenesis and immunology of oxyurids in pet reptiles. Coprological analyses for parasite detection should be mandatory before tortoises are transferred to a new owner, animal group, or public and private enclosures such as zoos. We advocate for regular health screenings in pet tortoises and, if parasitic infections are diagnosed, adequate medication or alternative hygiene management should be considered to improve and maintain individual and population health.
\end{abstract}

Keywords: Exotic pets, Tortoise, Herpetology, Pet reptiles, Reptile medicine, Tortoise endoparasites

\footnotetext{
* Correspondence: malekhallinger@web.de

${ }^{1}$ Institute of Parasitology, Justus Liebig University Giessen, Giessen, Germany

²Exomed GbR, Berlin, Germany
}

(c) The Author(s). 2018 Open Access This article is distributed under the terms of the Creative Commons Attribution 4.0 International License (http://creativecommons.org/licenses/by/4.0/), which permits unrestricted use, distribution, and reproduction in any medium, provided you give appropriate credit to the original author(s) and the source, provide a link to the Creative Commons license, and indicate if changes were made. The Creative Commons Public Domain Dedication waiver (http://creativecommons.org/publicdomain/zero/1.0/) applies to the data made available in this article, unless otherwise stated. 


\section{Background}

Reptiles have become increasingly popular domestic pets worldwide, and significant reptile welfare problems are linked to international pet trade $[1,2]$. While several reptile species obtainable as pet animals are bred successfully in captivity, other species are already taken from wild populations, reducing wild population sizes, and are used for pet trading or breeding [1-3]. Therefore, many tortoise species are critically endangered in the wild worldwide $[1,4,5]$. At the same time, tortoises are becoming increasingly popular domestic pets $[4,5]$. Exotic reptiles originating from the wild (including tortoises), in particular, are often infected with a variety of different invasive parasites, harbouring a broad spectrum of endogenous parasites including diverse species of protozoans, nematodes, cestodes, pentastomids, acanthocephalans and trematodes [6-10]. Tortoises specifically are not exclusively infected by gastrointestinal parasites such as oxyurids, ascarids and protozoans, but also carry diverse ectoparasites. Despite tortoises' popularity as pets, very little is known about the ectoparasite fauna affecting them in captivity [11] and thus needs further attention.

Reptiles held in captivity show higher prevalences and more efficient transmission for different monoxenous parasitoses than wild reptiles, including those caused by metazoan as well as protozoan parasites $[12,13]$. Plausible explanations for this phenomenon are mainly linked to direct life-cycles together with high tenacity of certain reptile exogenous parasitic stages, i.e. eggs, larvae, cysts and oocysts $[12,14]$. Pathogenicity of reptile parasitoses varies due to husbandry conditions, and poor husbandry hygiene can lead to clinically relevant massive parasitic burdens in a terrarium due to frequent reinfections [12]. Additionally, captivity stress can exacerbate existing parasitic infection as well as negatively impact on the host innate immune system $[12,15]$. Endoparasites can cause different clinical symptoms depending on parasite species and life-cycle, the age, sex, and health status of the animal host, housing conditions, and degree of infection $[12,16]$. In severe parasitoses, developmental disorders or even mortality can occur. Additionally, limited space and reinfection or superinfection can be critical for the survival of a captive-held reptile [3, 12]. Even more importantly, several reptile-borne parasites and bacteria exhibit zoonotic potential. For example, Salmonella enterica and S. bongori, their subspecies and serovariants $[12,17,18]$, pentastomids, such as Porocephalus spp. and Armillifer spp. in American and African snakes and Raillietiella spp. in snakes and geckos [8, 18], cestodes $[19,20]$, nematodes, e.g. Trichinella spp. in crocodiles [21] and Cryptosporidium spp. [22, 23] have been discussed as relevant anthropozoonotic parasites. Reptile-borne anthropozoonoses are also common in countries where reptiles are exploited for consumption as well as traditional medicinal and ethnic practices [8, 21]. There, common infection sources are the ingestion of raw or insufficiently cooked reptile meat, the usage of reptile meat as compresses to heal wounds or abscesses and drinking of exogenous water with contaminated parasite life-cycle stages $[8,19,20]$.

In the case of captive tortoises, parasitological investigations performed recently in other European countries $[13,14,16,24,25]$ revealed high and strongly varying prevalence (43-82\%) of gastrointestinal parasites in tortoises. The assessment methods in parasitological studies on tortoises varies strongly, making inter-study comparisons challenging. Some studies focused on dead or sick animals [13]. A study by Pasmans et al. on captive tortoises in Germany showed parasite infection prevalence but did not investigate commensalism and parasite-derived pathogenicity nor tortoise species, sex, age or nutrition status [12, 22]. Other reports focused on therapy options and prevalence [26], whereas others focused on oxyurid-infected tortoises [27, 28]. Further tortoise studies exclusively examined imported, sick or dead animals [12] without addressing current parasitic prevalence in pet tortoise populations.

Therefore, the aim of the current study is to provide new data on the prevalence of gastrointestinal parasites within the captive pet tortoise population in Germany and to discuss potential impact of these parasites on animal and public health.

\section{Methods}

\section{Faecal samples}

To obtain representative data for the prevalence of the gastrointestinal endoparasites affecting pet tortoises in Germany, we performed a stratified randomized sample of the entire captive population of Germany. We performed coprological analyses of a total of 1005 faecal samples, collected from 19 different tortoise species (Table 1), from November 2015 to December 2016. Analyzed faecal samples originated from animals either owned privately or held in German zoos, and were posted to the Exomed Laboratory in Berlin, Germany. We examined all samples by using saline faecal smears for general parasitological diagnosis.

Due to controversial issues recording tortoise phylogenetic position of Chelonia [11, 29], we here investigated exclusively faecal samples from terrestrial and major-herbivore species [30-35]. All analysed tortoises belonged to the family Testudinae $[11,29]$ and contained mainly European species (773 out of 1005 tortoises). Additionally, Exomed GbR clients were asked to provide a printed form delineating animals' signalment (i.e. species, sex, age), husbandry conditions (e.g. origin of tortoise, time in owner's possession, individual/group 
Table 1 Examined faecal samples of tortoises and origin of sender (total $n=1005$ )

\begin{tabular}{llll}
\hline Tortoise species & Common name & No. examined & Origin (private/vet/zoo) \\
\hline Testudo hermanni & Hermann's tortoise & 597 & $491 / 105 / 1$ \\
Unkown species & - & 169 & $143 / 26 / 0$ \\
T. graeca & Common tortoise & 65 & $42 / 21 / 2$ \\
T. horsfieldii & Horsefield's tortoise & 61 & $38 / 23 / 0$ \\
T. marginata & Marginated tortoise & 50 & $43 / 7 / 0$ \\
Stigmochelys pardalis & Leopard tortoise & 11 & $6 / 4 / 1$ \\
Centrochelys sulcata & African spurred tortoise & 10 & $8 / 1 / 1$ \\
Geochelone elegans & Indian star tortoise & 10 & $8 / 2 / 0$ \\
Chelonoidis carbonaria & Red-footed tortoise & 7 & $4 / 1 / 2$ \\
Aldabrachelys gigantea & Aldabra giant tortoise & 5 & $3 / 1 / 1$ \\
T. kleinmanni & Egyptian tortoise & 4 & $3 / 0 / 1$ \\
Malachoserus tornieri & Pancake tortoise & 4 & $1 / 1 / 2$ \\
Geochelone platynota & Burmese star tortoise & 3 & $0 / 0 / 3$ \\
Astrochelys radiata & Radiated tortoise & 3 & $1 / 1 / 1$ \\
Indotestudo elongata & Elongated tortoise & 2 & $2 / 0 / 0$ \\
Pyxis arachnoides & Spider tortoise & 2 & $2 / 0 / 0$ \\
Kinixys bellinia & Bell's Hinge-backed tortoise & 1 & $1 / 0 / 0$ \\
Manouria impressa & Impressed tortoise & 1 & $1 / 0 / 0$
\end{tabular}

housing, indoor/outdoor enclosure), previous parasitological examinations, and any anthelminthic treatments, labelled with the same reference number as corresponding faecal sample.

To ensure that all samples could be analyzed within $24 \mathrm{~h}$ of arrival, we encouraged tortoise owners to sample only fresh faeces, and to send these samples to our laboratory immediately. On arrival, samples were randomized, numbered, and stored at $4{ }^{\circ} \mathrm{C}$. We conducted a macroscopic examination of each faecal sample with a direct wet (saline) preparation according to Cooper [36]. By mixing $10 \mathrm{~g}$ of faeces at a ratio of $1: 1$ with $0.9 \%$ saline solution, a uniform solution was created. This solution allowed us to simultaneously identify different stages of both helminths and protozoans. Fifty millilitres of this solution was carefully placed on glass coverslides and gently covered by glass cover slips $(22 \times 22 \mathrm{~mm})$. Examination was performed at $100 \times$ and $400 \times$ magnification under a light microscope (Axio Imager M1, Zeiss, Jena, Germany). Counts of metazoan parasitic eggs and of protozoan trophozoites, cysts and oocysts were estimated.

We identified nematode eggs (e.g. oxyurids, ascarids and strongylids) and protozoan trophozoites, cysts and oocysts (e.g. Balantidium, Nyctotherus, Hexamita and Cryptosporidium) based on morphological/morphometric descriptions reported elsewhere $[3,6,7,28,37]$. A faecal sample was categorized as 'positive', when at least one stage of a potentially health-compromising described endoparasite was found. A sample containing exclusively non-pathogenic or facultative parasitic genera (i.e. Balantidium, Nyctotherus, Blastocystis, Trimitus and other flagellated protozoans) was classified as 'negative', unless it contained an extraordinary high number of flagellates, trophozoites or cysts according to previous reports [12, 16, 37, 38].

\section{Tortoise necropsies}

We necropsied a total of 49 tortoise corpses of at least eight different tortoise species at the Exomed Laboratory (see Table 2). We collected anamnestic data as described in the previous section for faecal samples. External examinations and necropsies were performed according Rataj et al. [13]. Additionally, we performed pathohistological examinations. The carcasses of most of tortoises had been freshly frozen prior to shipping to the Exomed Laboratory for post-mortem examination. The digestive tract was systematically examined for the presence of endoparasites. Intestinal contents were examined further by using saline faecal smears. Morphological identification of endoparasites was conducted under a light microscope (Axio Imager M1, Zeiss) equipped with a digital camera (AxioVision Software).

\section{Microbiology}

If requested by the owner, we performed selectively bacterial and fungal isolation. Swabs of faeces or of the coelom 
Table 2 Performed necropsies of tortoises, tortoise species and origin of sender $(n=49)$

\begin{tabular}{llll}
\hline Tortoise species & Common name & No. examined & Origin (private/vet/zoo) \\
\hline T. hermanni & Hermann's tortoise & 20 & $17 / 2 / 1$ \\
Unkown species & - & 7 & $4 / 3 / 0$ \\
T. horsfieldii & Horsefield's tortoise & 5 & $5 / 0 / 0$ \\
T. graeca & Common tortoise & 5 & $2 / 3 / 0$ \\
Stigmochelys pardalis & Leopard tortoise & 5 & $5 / 0 / 0$ \\
T. kleinmanni & Egyptian tortoise & 2 & $2 / 0 / 0$ \\
Pxyis arachnoides & Spider tortoise & 2 & $0 / 0 / 2$ \\
Centrochelys sulcata & African spurred tortoise & 1 & $1 / 0 / 0$ \\
Geochelone chilensis & Argentine tortoise & 1 & $1 / 0 / 0$ \\
Manouria impressa & Impressed tortoise & 1 & $1 / 0 / 0$
\end{tabular}

were inoculated on sheep blood agar (5\%), MacConkey agar and Sabourand dextrose agar (SDA) (BioMerieux, Charbonnier les Bains, France), respectively. Bacterial isolates were identified by Gram straining, oxidase and katalase test, as well as a commercial API 20E/NE kit (BioMerieux) as described for ectothermic vertebrates, such as fish [39].

\section{Results}

\section{Geographical origin of faecal samples, tortoise species} and occurring endoparasites

Geographical origin and tortoise species included in this parasitological survey are listed in Fig. 1 and Table 1. Within this survey, 19 different tortoise species were examined. The origin of the samples is visualized on a geographical map of Germany (Fig. 1). In total, five different metazoan parasite species, all belonging to the class Nematoda, were recorded (Tables 3 and 4). Among these nematodes, oxyurid eggs were the most common helminth ova identified in $43.2 \%$ of the samples from 14 out of 19 different tortoise species. In contrast, only 12 samples (0.1\%) contained Angusticaecum spp. eggs, three samples contained Strongyloides spp. eggs (0.003\%) and one sample contained heterakid eggs (0.001\%). A complete list of parasite species identified in the study is shown in Table 3. All nematode species reported here have pathogenic relevance for tortoises, and a negative impact on individual/population health. Seasonal oxyurid infection rates differed significantly (Chi-square test: $\left.X^{2}=10.97, d f=1, P<0.001\right)$, being higher in winter $(35.53 \%)$ than in summer $(46.66 \%)$ (see Fig. 2a, b and Table 5). Also, oxyurid infection rates varied with age (Chi-square test: $\chi^{2}=11.73, d f=1, P<0.001$ ), such that individuals older than five years were infected less frequently $(38.57 \%)$ than juveniles younger than five years of age (52.04\%). No significant correlation in oxyurid burdens could be detected in relation to other factors such as tortoise species, sex, group size and maintenance conditions (Table 5).
The diversity of the protozoan parasites was greater than that of helminths since seven species were identified in total but with lower prevalences (see Table 3). Species of at least three different genera of intestinal flagellates, i.e. Hexamita (0.007\%), Tritrichomonas $(0.004 \%)$ and facultative pathogenic flagellates such as Hexamastrix spp. and Trimitus spp. (0.001\%), two different genera of amoeba [Hartmanella (0.001\%) and Entamoeba (0.005\%)], one ciliate genus Balantidium spp. (0.007\%), and yeast-like Blastocystis spp. $(0.002 \%)$ occurred in tortoise faecal samples. Microscopy did not reveal Cryptosporidium oocysts in any of the faecal samples. Although representatives of the ciliate genus Nyctotherus were commonly found in faecal samples, these were not quantified, since the species of this genus are considered non-pathogenic for tortoises and are found in high prevalences in herbivorous tortoises without clinical symptoms [12]. In a T. hermanni tortoise, we found high numbers of Balantidium trophozoites accompanied by facultative pathogenic bacteria (Stenotrophomas maltophila and Morganella morganii) and in a Geochelone elegans tortoise infected with Balantidium spp. clinical signs such as anorexia and severe debilitation were reported. Illustrations of selected parasite stages and histopathological findings are depicted in Figs. 2 and 3. Collected data (e.g. tortoise age, weight, gender and diagnosed parasites in the corresponding faecal sample) are provided in Additional file 1: Table S1.

\section{Necropsies}

In total, 49 individual tortoises from at least eight different species were dissected (for details see Table 2). Of these, 19 tortoises were adults, 25 animals were juveniles, and in 6 cases no age-related data were obtained. In total, 38 tortoises $(77.6 \%)$ tested positive for endoparasite infections (Table 4), 12 tortoises (24.4\%) died likely due to severe oxyuridosis, and two tortoises (4.08\%) died of severe Hexamita spp. Infections. Other contributors to tortoise deaths were gout disease ( $n=11 ; 22.45 \%)$, viral infections [Picornavirus 


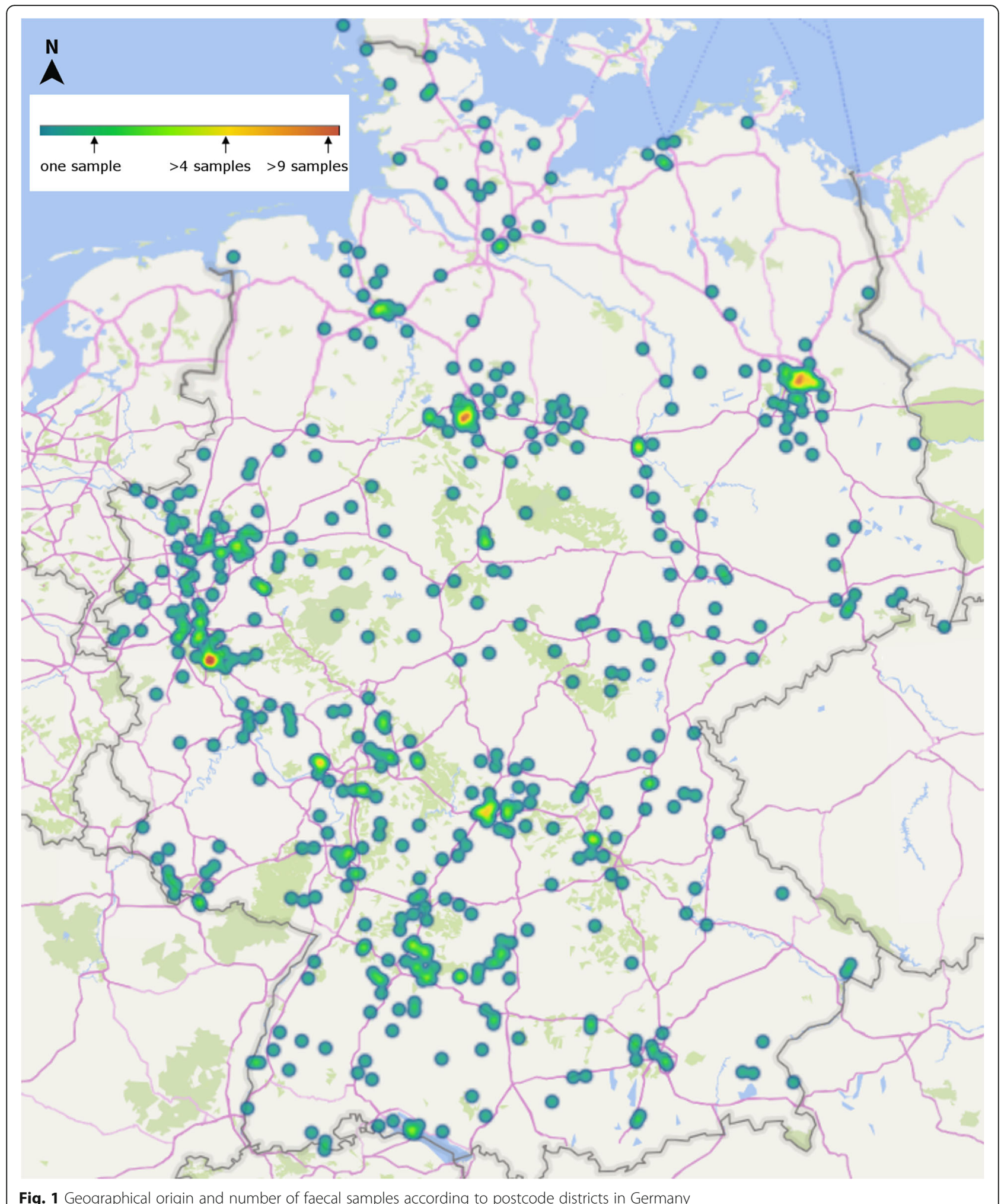

Fig. 1 Geographical origin and number of faecal samples according to postcode districts in Germany

( $n=6 ; 12.25 \%)$, Herpes virus $(n=3 ; 6.12 \%)]$, chronical nephrosis $(n=3 ; 6.12 \%)$, bacterial infections $(n=2 ; 4.08 \%)$, systemic mycosis $(n=1 ; 2.04 \%)$, cachexia and osteomalacia
( $n=1 ; 2.04 \%)$, intoxication $(n=1 ; 2.04 \%)$ and sand obstipation $(n=1 ; 2.04 \%)$. In six tortoises $(12.25 \%)$ the final death aetiology could not be identified (Fig. 4). 
Table 3 Number and percentage of positive tortoises regarding infection with gastrointestinal endoparasites (total $n=1005 ; 459$ positive and 546 negative)

\begin{tabular}{|c|c|c|}
\hline Parasite species & No. of positive (\%) & Host species $(n)$ \\
\hline Oxyurid nematode (Tachygonetria sp.) & $434(43.2)$ & $\begin{array}{l}\text { T. hermanni (248); unknown species (94); T. marginata (28); T. graeca (21); } \\
\text { T. horsfieldii (19); Stigmochelys pardialis (5); Centrochelys sulcata (5); } \\
\text { Geochelone elegans (4); Chelonoidis carbonaria (2); T. kleinmanni (2); } \\
\text { Pyxis arachnoides (2); Malacochersus tornieri (1); Chersina angulate (1); } \\
\text { Aldabrachelys gigantea (1); Astrochelys radiata (1) }\end{array}$ \\
\hline Ascarid nematode (Angusticaecum sp.) & $12(0.01)$ & T. hermanni (5); unknown species (5); Stigmochelys pardalis (1); C. sulcata (1) \\
\hline Hexamita sp. & $7(0.007)$ & T. hermanni (5); Geochelone elegans (1); Chelonoidis carbonaria (1) \\
\hline Balantidium sp (cysts) & $7(0.007)$ & T. hermanni (5); C. sulcata (1); Geochelone platynota (1) \\
\hline Trichomonas sp. & $4(0.004)$ & T. hermanni (4) \\
\hline Strongyloid nematode (Strongyloides sp.) & $3(0.003)$ & unknown species (2); Geochelone elegans (1) \\
\hline Entamoeba sp. (cysts) & $5(0.005)$ & $\begin{array}{l}\text { T. hermanni (1); Geochelone elegans (1); Chelonoidis carbonaria (1); } \\
\text { unknown species (1) }\end{array}$ \\
\hline Heterakid nematodes & $1(0.001)$ & Geochelone elegans (1) \\
\hline Hartmanella sp. (Limax amoeba) & $1(0.001)$ & Geochelone elegans (1) \\
\hline Blastocystis sp. & $2(0.002)$ & T. hermanni (1); Geochelone elegans (1) \\
\hline Facultative pathogen flagellates (Trimitus sp.) & $2(0.002)$ & T. horsfieldii (1); Geochelone elegans (1) \\
\hline
\end{tabular}

In total, 22 tortoises (44.9\%) showed macroscopic and histological signs for metabolic bone disease (MBD), and 15 of these $(68.18 \%)$ were infected with oxyurids (e.g. Tachygonetria spp.) and also showing signs for nephrosis/nephritis. Although the factors 'oxyurid burden' and factor 'MBD' correlated positive (Fisher's exact test: $P=0.038$ ), higher oxyurid burdens could not be identified as the only aetiological cause for MBD. An overview of isolated bacteria in combination with pathological diagnosis or reported clinical signs together with parasitic infection is given in the Additional file 2: Table S2.

\section{Discussion}

Gastrointestinal endoparasites in pet tortoises have been investigated in several European countries [12-14, 16, $24,38]$. These studies report extremely high prevalence of oxyurid infections in tortoises kept in captivity. These findings were consistent with high oxyurid prevalence observed in our study (43.18\%) and with our even higher prevalence recorded in dissected tortoises (57.14\%). Oxyurids (pinworms) in tortoises are frequently reported $[12-14,16,25,38]$. Studies at the generic level revealed the presence of Tachygonetria, Thaparia, Mehdiella and Alaeuris quite abundantly in tortoises of all ages [25, 27]. Oxyurid infections are proposedly tolerated and also to have rather low pathogenic effects on parasitized tortoises. The peculiar features of the large intestine of tortoises makes it plausible to assume that these nematodes have evolutionarily adapted to the tortoise gut microhabitat. Even an equilibrium of parasite-host-interactions has been postulated [28]. Moreover, oxyurids might be beneficial for certain tortoise species: some oxyurid-infected juvenile tortoises showed improved nutrient uptake and digestibility for most food components, since oxyurid nematodes might help to break up faecal masses, thereby preventing constipation [40]. Furthermore, oxyurids might contribute regulation of the bacterial flora in the caecum of herbivorous reptile hosts by feeding on bacteria [28].

Table 4 Number and percentage of positive tortoise corpses regarding to infestation with potentially health-compromising endoparasites (total $n=49$ / 38 positive and 7 different gastrointestinal parasites detected)

\begin{tabular}{lll}
\hline Parasite species & No. of positive (\%) & Host species $(n)$ \\
\hline Oxyurid nematode (Tachygonetria sp.) & $28(57.14)$ & T. hermanni (14); unknown species \\
Balantidium sp. (cysts) & $3(6.12)$ & $\begin{array}{l}\text { T.horsfieldii (3); T. graeca (3); T. kleinmanni (1); } \\
\text { Stigmochelys pardalis (1); G. sulcata (1) }\end{array}$ \\
Hexamita sp. & $2(4.08)$ & Manouria impressa (1); Pyxis arachnoides (1) \\
Blastocystis sp. & $2(4.08)$ & Pyxis arachnoides (1); unknown species (1) \\
Entamoeba sp. (cysts) & $2(4.08)$ & Pyxis arachnoides (1); unknown species (1) \\
Heterakid nematodes & $2(4.08)$ & Stigmochelys pardalis (2) \\
Strongyloid nematode (Serpinema sp.) & $1(2.04)$ & unknown species (1) \\
Proataracis sp. & $1(2.04)$ & T. hermanni (1) \\
\hline
\end{tabular}




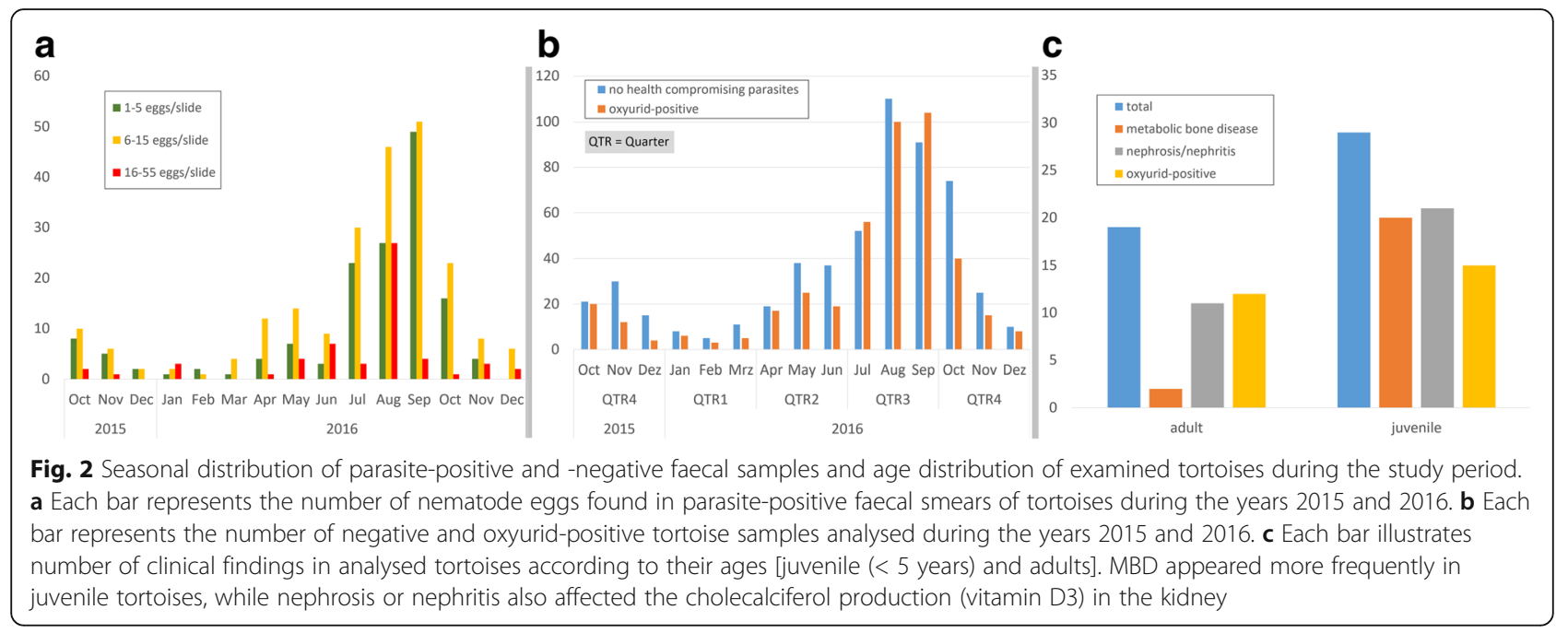

However, massive oxyurid infections can lead to severe malabsorption including clinical symptoms such as anorexia and diarrhoea, impaction, chronic weight loss and even sudden death $[12,40]$. Such oxyurid-derived pathogenicity is mainly linked to the monoxenous life-cycle and histiotrophic phase of oxyurid larvae, limited space for tortoises in captivity, low heterogeneity of oxyurids, and their ability to survive inside hibernating tortoises [12, 28, 41]. Juvenile tortoises in particular are affected by clinical oxyuridosis [28], since the life-cycle of oxyurids is completed within no more than 40 days. In our study, severe oxyuridosis was frequently (57.14\%) diagnosed post-mortem in tortoises and was the predominant cause of death for many $(24.49 \%)$ individuals included in necropsies.

Table 5 Statistical analysis of specific risk factors for oxyuridosis from data obtained by pet owners

\begin{tabular}{|c|c|c|c|c|c|}
\hline Factor & Sample size & No. of negative (\%) & No. of oxyurid-positive (\%) & Chi-square $^{a}$ & $P$-value (two-sided) \\
\hline Sender & 991 & & & 16.28 & $<0.001^{b}$ \\
\hline Private & 798 & $426(53.4)$ & $372(46.6)$ & & \\
\hline Veterinary doctor & 193 & $134(69.4)$ & $59(30.6)$ & & \\
\hline Tortoise species & 452 & & & 2.97 & 0.086 \\
\hline T. hermanni & 402 & $222(55.2)$ & $180(44.8)$ & & \\
\hline T. graeca & 50 & $34(68.0)$ & $16(32.0)$ & & \\
\hline Tortoise sex & 725 & & & 1.43 & 0.231 \\
\hline Male & 253 & $150(59.3)$ & $103(40.7)$ & & \\
\hline Female & 472 & $258(66.7)$ & $214(45.3)$ & & \\
\hline Tortoise age & 644 & & & 11.73 & $<0.001^{\mathrm{b}}$ \\
\hline Juvenile; $<5 a$ & 294 & $141(48.0)$ & $153(52.0)$ & & \\
\hline Adult; $>5 a$ & 350 & $215(61.4)$ & $135(38.6)$ & & \\
\hline Group size & 765 & & & 0.99 & 0.321 \\
\hline Group facility & 648 & $350(54.0)$ & $298(46.0)$ & & \\
\hline Single enclosure & 117 & $69(60.5)$ & $48(41.0)$ & & \\
\hline Keeping conditions & 111 & & & 0.32 & 0.571 \\
\hline Free- range & 94 & $62(66.0) /$ & $32(34.0)$ & & \\
\hline Terrarium & 11 & $10(58.8)$ & $7(41.2)$ & & \\
\hline Sampling season & & & & 10.968 & $<0.001^{\mathrm{b}}$ \\
\hline October-March & 318 & $205(64.5)$ & $113(35.5)$ & & \\
\hline April-September & 688 & $367(53.3)$ & $321(46.7)$ & & \\
\hline
\end{tabular}

${ }^{a}$ Chi-square test, $d f=1, a=0.001$; critical $\chi^{2}$ value $=10.82$ )

${ }^{\text {b }}$ Significant difference 

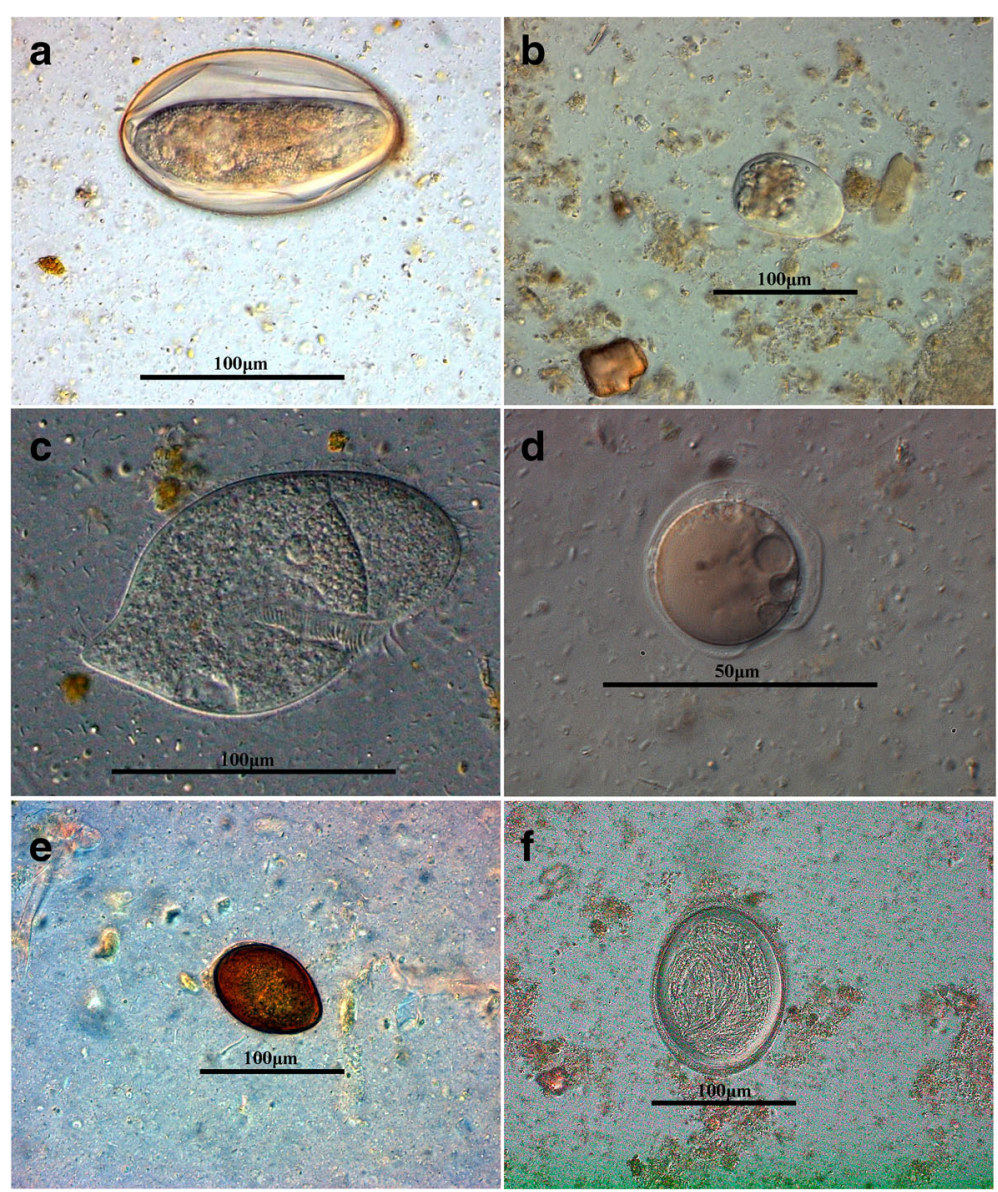

Fig. 3 Light microscopy photomicrographs of parasite life-cyste stages found in faecal samples of German pet tortoises. a Oxyurid egg from a Marginated tortoise (Testudo marginata). b lodide-stained Entamoeba trophozoite from a Hermann tortoise (Testudo hermanni). $\mathbf{c}$ Ellipsoidalshaped Balantidium sp. trophozoite with a long cytostome and oral cavity, from a Hermann tortoise (T. hermanni). d Blastocystis sp. cyst from a Hermann tortoise (T. hermanni). e Nyctotherus sp. cyst in the faeces of an Indian Star tortoise (Geochelone elegans). f Angusticaecum sp. egg from a Hermann tortoise containing infectious L1 (T. hermanni)

Moreover, oxyurid infections were often combined with other associated, factorial diseases such a liver degeneration, renal diseases (nephrosis/nephritis) or metabolic bone disease (MBD). Therefore, we advocate that oxyuridosis should be considered an important parasitosis under unfavourable husbandry conditions (i.e. inappropriate food supply, inadequate access to UV light, too dry conditions and insufficient maintenance hygiene) because of owners' lack of knowledge, especially for juvenile tortoises ( $<5$ years) [12]. Since other endoparasitic infections, such as Cryptosporidium spp. and Balantidium spp. infections, can lead to enteral calcium malabsorption in tortoises, also infections with oxyurids in juvenile tortoises might result in severe calcium deficiency. However, although we found that MBD rate increased with oxyurid burden, we were unable to single out increased oxyurid burdens as the only aetiological cause for MBD. Seeing that most study animals were also diagnosed with nephritis or nephrosis in conjunction with MBD, a secondary renal hyperparathyroidism might be linked to MBD symptoms (Fig. 2c).

In this study, oxyurid infections were more common in young tortoises $(<5$ years of age), than in adults (Table 5 ). Differences in oxyurid egg shedding in relation to tortoise age are poorly understood, and host immune responses, coprophagy or oxyurid species-specific effects might play a role in pathogenesis in juvenile tortoises [12, 28].

More samples were oxyurid-positive in summer (April-September) than in winter (October-March) (see Fig. 1b, c and Table 5). Reasonably, newly purchased tortoises with an unknown parasite status are frequently tested by the owners during spring/summer. Also, after diagnosis of oxyuridosis, an inefficient deworming, inadequate quarantine, false negative faecal samples or even no confirmation of efficient deworming before entering hibernation period could explain our findings.

In contrast to oxyuridosis, prevalences of ascarid infections, most probably Angusticaecum holopterum [16, 24], 

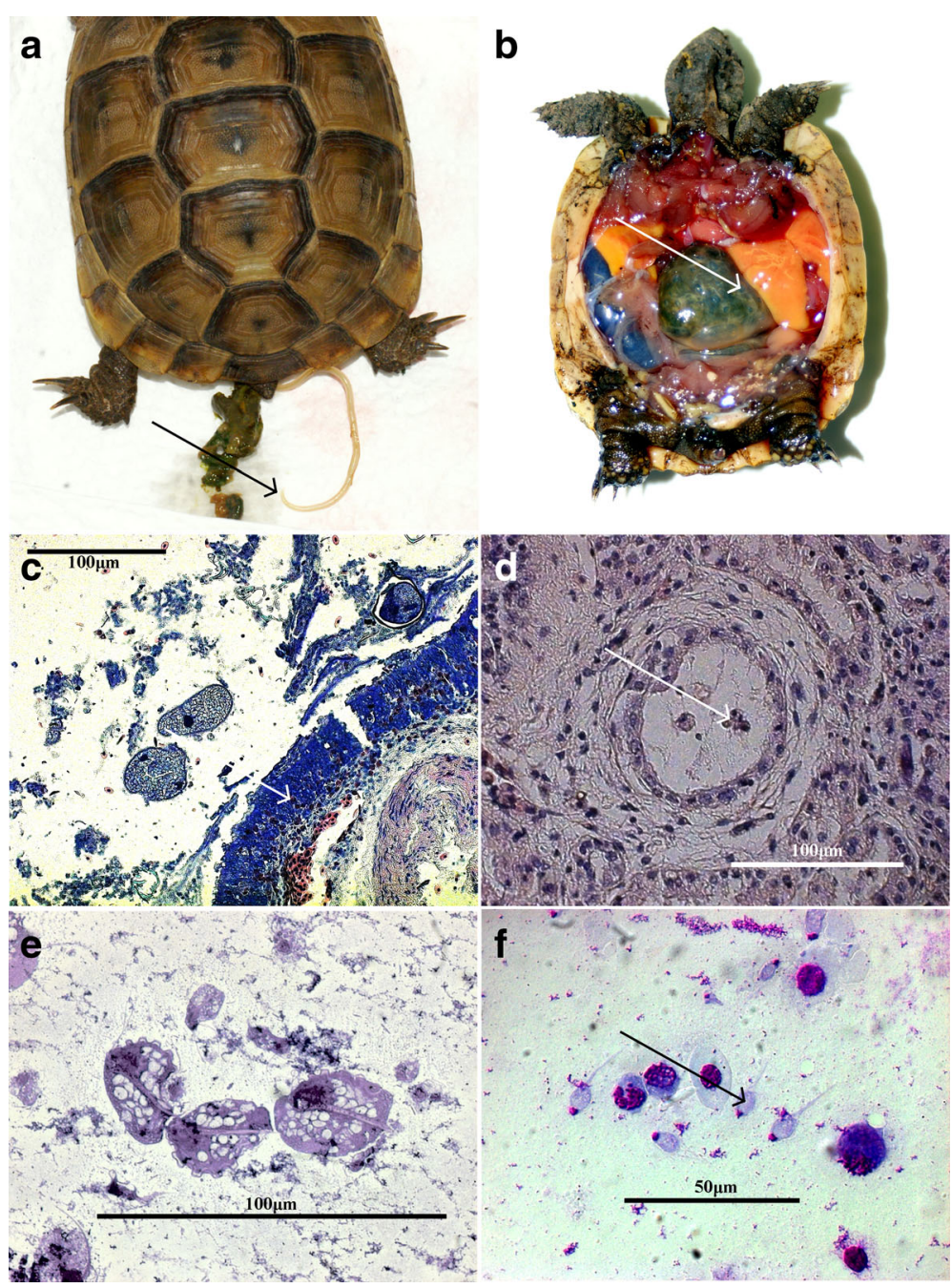

Fig. 4 a Massive Angusticaecum sp. infection in a Hermann tortoise (Testudo hermanni) (leading to spontaneous expulsion of an adult nematode (arrow). b Lethal oxyurid infection in a necropsied juvenile tortoise (T. hermanni) with a massive colonic oxyurid infection (indicated by an arrow) associated with fatty liver degeneration (i.e. egg-yolk yellow liver). c Balantidium-associated enteritis (HE staining): free Balatidium sp. trophozites detected in the gastrointestinal lumen neighboring an eosinophilic-infiltrated (indicated by arrow) mucosa (T. hermanni, 400x). d Subchronic hexamitiosis (HE staining): interstitial nephritis with lymphocytic infiltration caused by Hexamita sp. Flagellated Hexamita trophozoites can be detected in the renal tubule lumen (indicated by arrow) of a Spider tortoise (Pyxis arachnoides,1000X). e Three trichomonad trophozoites with undulating membrane extending almost to their entire body length (Giemsa staining, 1000X). $\mathbf{f}$ Impression preparation of a kidney containing Hexamita sp. trophozoites with characteristic anterior protruded nuclei (arrow, Giemsa staining, 1000x)

in sampled tortoises were extremely low $(n=12 ; 0.01 \%$ ). Half of these ascarid-positive animals were co-infected with oxyurid species (Proatracis sp. Was found in one necropsied tortoise). Ascarid prevalences of $0.01 \%$ in our study were very low compared with those reported in other Europe-based tortoise studies which reported prevalences between $8.5-28.0 \%[12,16]$ and even up to $56.9 \%$ [13] for tortoises maintained in captivity. For Germany, an ascarid prevalence of $1.5-2.7 \%$ in captive tortoises was previously reported [12] which is still higher than reported in the current study. Very low prevalences of ascarid infections observed in our study might be linked to diagnostic technique used here. Methods used in other studies combining flotation, the McMaster technique, and/or SAF (sodium acetate acetic acid formalin) methods might thus be more appropriate diagnostic tools to detect ascarid infections in reptiles $[3,13]$. In addition, irregular and self-consistent, veterinary-independent anthelmintic treatments and/or inadequate hygiene conditions of owners might have influenced ascarid prevalences. In this study, the youngest ascarid-infected tortoise was two years of age and the oldest ten years, indicating that ascariosis likely affects all age groups of tortoises. Also, we found one ascarid-positive animal, a juvenile leopard tortoise (Stigmochelys pardalis), which showed an unusual gastrointestinal flora while the presence of 
potentially pathogenic microorganisms such as Acintobacter sp. and Aspergillus sp. [42-44] were diagnosed. Currently, species of the ascarid genus Angusticaecum in tortoises seems more pathogenic than oxyurids since the life-cycle of Angusticaecum spp. includes larval migration and further development in various organs, and is associated with anorexia, exsiccosis and weight loss [14, 16]. Eggs of Angusticaecum spp. have a three-layered shell and a sticky external mucopolysaccharide chain layer, which makes these eggs adhesive to the surface of environmental structures and resistant to commonly used disinfectants. Due to the high tenacity of Angusticaecum spp. eggs, the management or even eradication of Angusticaecum infections in tortoises can thus become a major exhausting challenge.

The low prevalence of Strongyloides spp. eggs in our study is in contrast with Ratai et al. [13], who reported a Strongyloides prevalence of $3.7 \%$ in necropsied tortoises. Only one animal was infected with heterakids $(0.001 \%)$ which was much lower than prevalences published elsewhere [12]. Heterakid nematodes of the genera Meterakis and Africana are known to parasitise in Testudinae [45]. Heterakids do not commonly parasite in herbivorous tortoises, but in more-insectivorous hosts such as chameleons and geckos, as well as insectivorous tortoises of the genus Kinixys [45, 46]. Since numerous heterakid species do not show strict host specificity [46], transmission to herbivorous tortoises might be possible when keeping them together with insectivorous reptile species, for instance in zoos.

In contrast to helminths, much less is known about occurrence and pathogenicity of intestinal protozoans in captive reptiles $[7,10]$. Species of most intestinal flagellate genera such as Trepomonas, Trimitus, Chilomastix and Retortamonas are not considered pathogenic, or their pathogenicity is still unknown [7, 12]. Conversely, the enteroflagellate Hexamita parva has been described as a pathogenic species due to its tendency to ascend towards organs connected to the gut, such as the kidneys, urinary bladder and liver [6]. Consistently, Hexamita-infection was the second-most frequent parasitosis found in this study. More importantly, hexamitosis occasionally resulted in fatal outcomes, thus supporting previous reports of its high pathogenicity $[6,12]$. In our epidemiological study, mortal hexamitosis was only surpassed by oxyuridosis, indicating the significance of hexamitosis in pet tortoises in Germany. Chronic hexamitosis in chelonian tortoises can result in severe tubular-interstitial nephritis, granulome formation, tubular necrosis, mineralization, gout, hyaline casts and even fibrosis [6, 12]. The high pathogenicity of $H$. parva presented in this study calls for more investigations on this neglected intestinal parasite.

We also identified potentially pathogenic protozoans (i.e. Tritrichomonas), and facultative parasites (i.e. Blastocystis) in pet tortoises [10, 37]. Blastocystis infections are often found in clinically healthy reptiles [37]. Moreover, due to its rather high prevalence in herbivorous tortoises without clinical symptoms [12], the ciliate genus $\mathrm{Nyc}$ totherus, with its species all are regarded to be apathogenic, was also identified in our study but not quantified. In contrast to Nyctotherus spp., Balantidium spp. can induce enteritis in heavily infected animals or by acting synergistically in association with other parasites [12, 14]. Confirmatively, one necropsied tortoise showed a severe Balantidium-derived colitis with a concomitant oxyurid infection. Balantidiasis in tortoises has generally been reported to be mostly non-pathogenic [14, 16]. Nevertheless, we note that one Geochelone elegans tortoise that displayed anorexia and severe debilitation, was also infected with high numbers of Balantidium trophozoites. In the colon of one necropsied $T$. hermanni tortoise, we found high numbers of Balantidium trophozoites accompanied by facultative pathogenic bacteria (Stenotrophomas maltophila and Morganella morganii) [42-44] evidencing the pathogenic potential of Balantidium.

The amoebae of the genus Hartmanella might infect tortoises kept in captivity but until now are still considered non-pathogenic parasites [7]. In contrast, other amoeba genera, such as Entamoeba, with its pathogenic species E. invadens, should be considered pathogenic since they can cause anorexia, watery diarrhoea and epizootic amebiasis in herbivorous tortoises [7]. As a general recommendation, infections with these parasites should always be considered in routine reptile diagnosis by veterinarians, particularly when corresponding clinical symptoms are present.

Overall, we found neither eggs of cestodes, trematodes or pentastomids nor oocysts of Cryptosporidium spp. Since reptiles act as definitive hosts for pentastomids, special attention for 'One Health' reasons should be paid to these parasitic crustaceans. Some pentastomid species have anthropozoonotic potential and are largely unknown to the scientific community [8]. According to the indirect the life-cycle of pentastomids, only carnivorous or piscivorous chelonians should be affected and act as definitive hosts [8]. Our large-scale study $(n=1005)$ suggests that herbivorous tortoises held in German private homes or zoos are generally not infected with pentastomids. Herbivorous tortoises thus likely play a neglectable role in human pentastomid-derived infections.

While we did not find any oocysts of Cryptosporidium in this study, cryptosporidiosis occurs in tortoises, manifesting in classical enteritis symptoms such as chronic diarrhoea, weight loss and/or unusually soft faeces due to maldigestion [47-49]. A recent study from the Czech Republic showed a Cryptosporidium prevalence of $11 \%$ in pet tortoises using microscopy- and PCR-analyses $(n=387)$ [50]. Saline faecal smears performed in the 
present study might have missed detection of minute Cryptosporidium oocysts (c.5 $\mu \mathrm{m}$ in size), thus the actual cryptosporidiosis prevalence might have been higher. Additionally, galled tree pollen in the faeces of free-ranging reptiles can cause false-positive results when saline smears are used for Cryptosporidium oocyst detection. Further epidemiological studies on cryptosporidiosis in pet tortoises are required using more sensitive methods such as carbol-fuchsin faecal smears, the usage of commercially available copro-ELISAs (e. g. ProSpecT ${ }^{\oplus}$ Cryptosporidium Microplate Assay), direct immunofluorescence (Meriflour ${ }^{\circ}$ ), or even Cryptosporidium-specific copro-PCR as previously proposed [50]. The zoonotic potential of reptile-derived Cryptosporidium species has recently been discussed [51, 52]. Until now, neither anthropozoonotic C. parvum/C. muris infections have been identified as transmissible to reptiles, nor have Cryptosporidium infections from reptiles to endotherms been demonstrated under experimental conditions to date $[53,54]$.

\section{Conclusions}

The infection of several pathogenic parasite species found in our epidemiological study calls not only for a faecal examination of tortoises prior to being introduced to a new owner, animal group, or enclosure, but also shows that endoparasite health screenings should be performed and, if diagnosed, appropriately medicated exclusively by veterinarians. Animal welfare and hygiene issues in particular, as well as illegal pet trade issues, demand that routine coprological diagnosis of parasitoses are recognised as a paramount aspect of reptile medicine. Based on this parasitological study, we advocate for further and more detailed research on this still neglected herpetological issue.

\section{Additional files}

Additional file 1: Table S1. Data obtained from necropsies and faecal samples such as date of receive, post code and information collected from pet owners such as age, husbandry conditions, gender, length, weight, species and diagnosed parasites. (XLSX $394 \mathrm{~kb}$ )

Additional file 2: Table S2. Isolated bacteria in pet tortoises from Germany; origin and species of tortoises regarding to the infestation with potentially health-critical endoparasites, performed microbiology and aetilogical death reason/ reported clinical signs. (DOCX $18 \mathrm{~kb}$ )

\section{Abbreviations}

ELISA: Enzyme-linked immunosorbent assay; MBD: Metabolic bone disease

\section{Acknowledgements}

This research was supported by Exomed GbR - Institute for Veterinary Medical Care of Lower Vertebrates and Other Exotic Pets, Berlin, and Institute of Parasitology, Gießen. We are thankful to our colleagues Frank Hausemann, Mathias Nolde, Nina Heindorf and Anna Dieudonné who provided assistance that greatly improved the research.

\section{Funding}

This research received no specific grant from any funding agency in the public, commercial or not-for-profit sectors.

\section{Availability of data and materials}

All data generated or analysed during this study are included in this published article and its additional files.

\section{Authors' contributions}

$\mathrm{FM}, \mathrm{AT}$ and $\mathrm{CH}$ conceived the study. $\mathrm{MJH}, \mathrm{CH}$ and $\mathrm{FM}$ were involved in the writing and design of the study and the drafting of the manuscript. All

authors read and approved the final manuscript.

Ethics approval and consent to participate

Not applicable.

\section{Consent for publication}

Not applicable.

\section{Competing interests}

The authors declare that they have no competing interests.

\section{Publisher's Note}

Springer Nature remains neutral with regard to jurisdictional claims in published maps and institutional affiliations.

Received: 24 January 2018 Accepted: 5 June 2018

Published online: 18 June 2018

References

1. Türkozan O, Özdemir A, Kiremit F. International testudo trade. Chelonian Conserv Bi. 2008:7:269-74.

2. Bush ER, Baker SE, Macdonald DW. Global trade in exotic pets 2006-2012. Conserv Biol. 2014;28:663-76.

3. Wolf D, Globokar Vrhovec M, Failing K, Rossier C, Hermosilla C, Pantchev N. Diagnosis of gastrointestinal parasites in reptiles: comparison of two coprological methods. Acta Vet Scand. 2014;56:44.

4. Rosen GE, Smith KF. Summarizing the evidence on the international trade in illegal wildlife. EcoHealth. 2010;7:24-32.

5. Karesh WB, Cook RA, Bennett EL, Newcomb J. Wildlife trade and global disease emergence. Emerg Infect Dis. 2005;11:1000-2.

6. Zwart P. Hexamitasis in tortoises. Vet Parasitol. 1975;1:175-83.

7. Scullion FT, Scullion MG. Gastrointestinal protozoal diseases in reptiles. J Exot Pet Med. 2009;18:226-78.

8. Paré JA. An overview of pentastomiasis in reptiles and other vertebrates. J Exot Pet Med. 2008;17:285-94.

9. Junker K, Riley J, Boomker J. Redescription of Diesingia megastoma (Diesing, 1836) Sambon, 1922, a pentastomid parasite from the South American terrapin Hydromedusa tectifera Cope. Syst Parasitol. 2003;56:211-8.

10. Juan-Sallés C, Garner MM, Nordhausen RW, Valls X, Gallego M, Soto S. Renal flagellate infections in reptiles: 29 cases. J Zoo Wildl Med. 2014;45:100-9.

11. Chiari Y, Cahais V, Galtier N, Delsuc F. Phylogenomic analyses support the position of turtles as the sister group of birds and crocodiles (Archosauria). BMC Biol. 2012;10:65

12. Pasmans F, Blahak S, Martel A, Pantchev N. Introducing reptiles into a captive collection: the role of the veterinarian. Vet J. 2008:175:53-68.

13. Rataj A, Lindtner-Knific R, Vlahović K, Mavri U, Dovč A. Parasites in pet reptiles. Acta Vet Scand. 2011;53:33.

14. Cervone M, Fichi G, Lami A, Lanza A, Damiani GM, Perrucci S. Internal and external parasitic infections of pet reptiles in Italy. J Herpetol Med Surg. 2016;26:122-30.

15. Grego KF, Gardiner CH, Catão-Dias JL. Comparative pathology of parasitic infections in free-ranging and captive pit vipers (Bothrops jararaca). Vet Rec. 2004;154:559-62.

16. Papini R, Manetti C, Mancianti F. Coprological survey in pet reptiles in Italy. Vet Rec. 2011;169:207.

17. Mermin J, Hutwagner L, Vugia D, Shallow S, Daily P, Bender J, et al. Reptiles, amphibians, and uuman Salmonella infection: a population-based, casecontrol study. Clin Infect Dis. 2004;38(Suppl. 3):253-61.

18. Magnino S, Colin P, Dei-Cas E, Madsen M, McLauchlin J, Nöckler K, et al. Biological risks associated with consumption of reptile products. Int J Food Microbiol. 2009:134:163-75.

19. Chang KH, Chi JG, Cho SY, Han MH, Han DH, Han MC. Cerebral sparganosis: analysis of 34 cases with emphasis on $C T$ features. Neuroradiology. 1992;34:1-8. 
20. Gong C, Liao W, Chineah A, Wang X, Hou BL. Cerebral sparganosis in children: epidemiological, clinical and MR imaging characteristics. BMC Pediatrics. 2012;12:155

21. Grange LR, Marucci G, Pozio E. Trichinella zimbabwensis in wild Nile crocodiles (Crocodylus niloticus) of South Africa. Vet Parasitol. 2009;161:88-91.

22. Xiao L, Sulaiman IM, Ryan UM, Zhou L, Atwill ER, Tischler ML, et al. Host adaptation and host-parasite co-evolution in Cryptosporidium: implications for taxonomy and public health. Int J Parasitol. 2002;32:1773-85. http://aem. asm.org/content/70/2/891.short.

23. Paiva PRSO, Grego KF, Lima VMF, Nakamura AA, da Silva DC, Meireles MV Clinical, serological, and parasitological analysis of snakes naturally infected with Cryptosporidium serpentis. Vet Parasitol. 2013;198:54-61. https://link. springer.com/article/10.1007/s00436-005-1384-9

24. Traversa D, Capelli G, lorio R, Bouamer S, Cameli A, Giangaspero A. Epidemiology and biology of nematodofauna affecting Testudo hermanni, Testudo graeca and Testudo marginata in Italy. Parasitol Res. 2005;98:14-20

25. Chávarri M, Berriatua E, Giménez A, Gracia E, Martínez-Carrasco C, Ortiz JM, et al. Differences in helminth infections between captive and wild spurthighed tortoises Testudo graeca in southern Spain: a potential risk of reintroductions of this species. Vet Parasitol. 2012;187:491-7.

26. Giannetto S, Brianti E, Poglayen G, Sorgi C, Capelli G, Pennisi MG, et al. Efficacy of exfendazole and fenbendazole against tortoise (Testudo hermanni) oxyurids. Parasitol Res. 2007;100:1069-73.

27. Thapar GS. Studies on the oxyurid parasites of reptiles. J Helminthol. 1925:3:83-150.

28. Forstner MJ. Ein Beitrag zur Kenntnis parasitischer Nematoden aus griechischen Landschildkröten. Zeitschrift für Parasitenkunde. 1960;20:1-22.

29. Crawford NG, Faircloth BC, McCormack JE, Brumfield RT, Winker K, Glenn TC. More than 1000 ultraconserved elements provide evidence that turtles are the sister group of archosaurs. Biol Lett. 2012;8:783-6.

30. Branch WR, Benn GA, Lombard AT. The tortoises (Testudinidae) and terrapins (Pelomedusidae) of southern Africa: their diversity, distribution and conservation. South African J Zool. 1995;30:91-102.

31. El Mouden EH, Slimani T, Ben Kaddour K, Lagarde F, Ouhammou A, Bonnet $X$. Testudo graeca graeca feeding ecology in an arid and overgrazed zone in Morocco. J Arid Environ. 2006;64:422-35.

32. Hailey A. Digestive efficiency and gut morphology of omnivorous and herbivorous African tortoises. Can J Zool. 1997:75:787-94.

33. Lagarde F, Bonnet X, Corbin J, Henen B, Nagy K, Mardonov B, et al. Foraging behaviour and diet of an ectothermic herbivore: Testudo horsfieldi. Ecography. 2003;26:236-42

34. Leuteritz TEJ, Lamb T, Limberaza JC. Distribution, status, and conservation of radiated tortoises (Geochelone radiata) in Madagascar. Biol Conserv. 2005; 124:451-61.

35. Rouag R, Ferrah C, Luiselli L, Tiar G, Benyacoub S, Ziane N, et al. Food choice of an Algerian population of the spur-thighed tortoise, Testudo graeca. Afr J Herpetol. 2008;57:103-13.

36. Cooper JE. In-practice and field techniques for the investigation of parasitic infections. J Exot Pet Med. 2009;18:289-98.

37. Teow WL, Ng GC, Chan PP, Chan YC, Yap EH, Zaman V, et al. A survey of Blastocystis in reptiles. Parasitol Res. 1992;78:453-5.

38. Mihalca AD, Gherman C, Ghira I, Cozma V. Helminth parasites of reptiles (Reptilia) in Romania. Parasitol Res. 2007:101:491-2.

39. Santos Y, Romalde JL, Bandín I, Magariños B, Núñez S, Barja JL, et al. Usefulness of the API-20E system for the identification of bacterial fish pathogens. Aquaculture. 1993;116:111-20.

40. Loukopoulos P, Komnenou A, Papadopoulos E, Psychas V. Lethal Ozolaimus megatyphlon infection in a green iguana (Iguana iguana rhinolopa). J Zoo Wildl Med. 2007:38:131-4.

41. Adamson ML, Petter AJ. Haplodiploidy in pharyngodonid (Oxyuroidea: Nematoda) parasites of Testudo graeca. Ann Parasitol Hum Comp. 1983; 58:267-73.

42. Cushing A, Pinborough M, Stanford M. Review of bacterial and fungal culture and sensitivity results from reptilian samples submitted to a UK laboratory. Vet Rec. 2011;169:390.

43. Keenan SW, Elsey RM. The good, the bad, and the unknown: microbial symbioses of the American alligator. Integr Comp Biol. 2015;55:972-85.

44. Joyner PH, Brown JD, Holladay S, Sleeman JM. Characterization of the bacterial microflora of the tympanic cavity of eastern box turtles with and without aural abscesses. J Wildl Dis. 2006:42:859-64.
45. Bouamer S, Morand S. Two new heterakid (Nematoda) species from Kinixys erosa (Schweigger, 1812) (Chelonii: Testudinidae) in the Democratic Republic of Congo. J Parasitol. 2007;93:639-45.

46. Baker MR. The systematics and zoogeography of Spinicaudinae and Meteterakinae (Heterakoidea: Nematoda) parasitic in reptiles and amphibians. Syst Parasitol. 1984;6:275-87.

47. Griffin C, Reavill DR, Stacy BA, Childress AL, Wellehan JFX. Cryptosporidiosis caused by two distinct species in Russian tortoises and a pancake tortoise. Vet Parasitol. 2010;170:14-9.

48. Richter B, Rasim R, Vrhovec MG, Nedorost N, Pantchev N. Cryptosporidiosis outbreak in captive chelonians (Testudo hermanni) with identification of two Cryptosporidium genotypes. J Vet Diagn Invest. 2012;24:591-5.

49. Traversa D, lorio R, Otranto D, Modrý D, Šlapeta J. Cryptosporidium from tortoises: Genetic characterisation, phylogeny and zoonotic implications. Mol Cell Probes. 2008:22:122-8.

50. Ježková J, Horcicková M, Hlásková L, Sak B, Kvetonová D, Novák J, et al. Cryptosporidium testudinis sp. n., Cryptosporidium ducismarci Traversa, 2010 and Cryptosporidium tortoise genotype III (Apicomplexa: Cryptosporidiidae) in tortoises. Folia Parasitol. 2016:14;63. https://www.ncbi.nlm.nih.gov/ pubmed/27827334.

51. Xiao L, Sulaiman IM, Ryan UM, Zhou L, Atwill ER, Tischler ML, et al. Host adaptation and host-parasite co-evolution in Cryptosporidium: implications for taxonomy and public health. Int J Parasitol. 2002;31:1773-85.

52. Paiva PRSO, Grego KF, Lima VMF, Nakamura AA, da Silva DC, Meireles MV. Clinical, serological, and parasitological analysis of snakes naturally infected with Cryptosporidium serpentis. Vet Parasitol. 2013:198:54-61.

53. Graczyk TK, Fayer R, Cranfield MR. Cryptosporidium parvum is not transmissible to fish, amphibians, or reptiles. J Parasitol. 1996;82:748-51.

54. Fayer R, Graczyk TK, Cranfield MR. Cryptosporidium transmissible to neonatal BALB/c mice (Mus musculus). J Parasitol. 1995;81:482-4.

\section{Ready to submit your research? Choose BMC and benefit from:}

- fast, convenient online submission

- thorough peer review by experienced researchers in your field

- rapid publication on acceptance

- support for research data, including large and complex data types

- gold Open Access which fosters wider collaboration and increased citations

- maximum visibility for your research: over $100 \mathrm{M}$ website views per year

At BMC, research is always in progress.

Learn more biomedcentral.com/submissions 